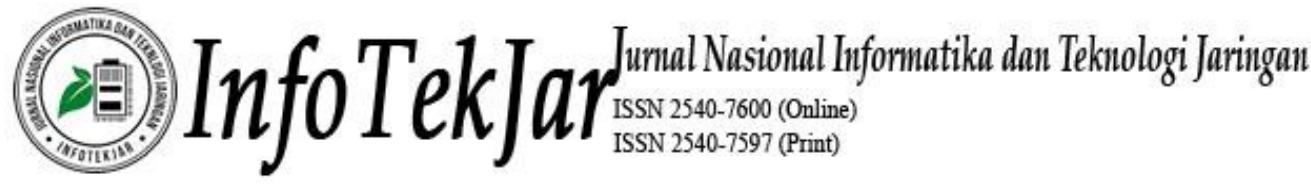

\section{MODEL ARSITEKTUR ARTIFICIAL NEURAL NETWORK PADA PELANGGAN LISTRIK NEGARA (PLN)}

\author{
Muhammad Noor Hasan Siregar \\ Universitas Graha Nusantara, Padangsidimpuan, Sumatera Utara, Indonesia \\ noor.siregar@gmail.com
}

\begin{abstract}
Abstrak - Perusahaan Listrik Negara (PLN) merupakan sebuah BUMN yang mengurusi semua aspek kelistrikan yang ada di Indonesia. Meningkatnya kebutuhan masyarakat akan listrik seiring tumbuhnya populasi membuat pelanggan listrik terus bertambah. Penelitian ini bertujuan untuk membuat sebuah model prediksi dengan memanfaatkan kecerdasan buatan yakni Jaringan saraf Tiruan dengan menggunakan algoritma Backpropogation. Data penelitian bersumber dan diolah oleh Badan Pusat Statistik Indonesia (https://www.bps.go.id). Data masukan adalah kelompok pelanggan PLN yang dibagi kedalan 5 kategori yakni Sosial, Rumah Tangga, Bisnis, Industri dan Publik dengan data jumlah pelanggan (2006-2015). Hasil penelitian menunjukkan bahwa 4 pengujian model arsitektur yaitu 5-10-1, 5-25-1, 5-10-25-1 dan 5-25-10-1 diperoleh model 5-25-1 adalah model arsitektur terbaik dengan parameter MSE Pelatihan 0,0009994101, MSE Pengujian 0,0011603685, Epoch 520 dan Akurasi 80\%. Diharapkan penelitian ini dapat memberikan prediksi kepada pihak PLN kedepanya tentang jumlah peningkatan pelanggan PLN mengingat listrik adalah salah satu kebutuhan masyarakat.
\end{abstract}

Keywords - pelanggan, Prediksi, Kecerdasan Buatan, Backpropogation, Jaringan Saraf Tiruan

\section{PENDAhUluan}

Pelanggan Listrik Negara adalah sebuah Badan Umum Milik Negara (BUMN) yang mengurusi semua aspek kelistrikan yang ada di Indonesia. Berdasarkan data Perusahaan Listrik Negara, jumlah pelanggan listrik hingga akhir Agustus 2015 mencapai 61,2 juta pelanggan. Jumlah tersebut naik 3,7 persen dibanding akhir 2014, yakni 57,5 juta pelanggan. Selama periode 2011-2015, jumlah konsumen listrik rata-rata tumbuh 7,45 persen per tahun. Berikut ini grafik jumlah pelanggan listrik negara yang terus meningkat seiring kebutuhan masyarakat akan listrik yang terus bertambah.

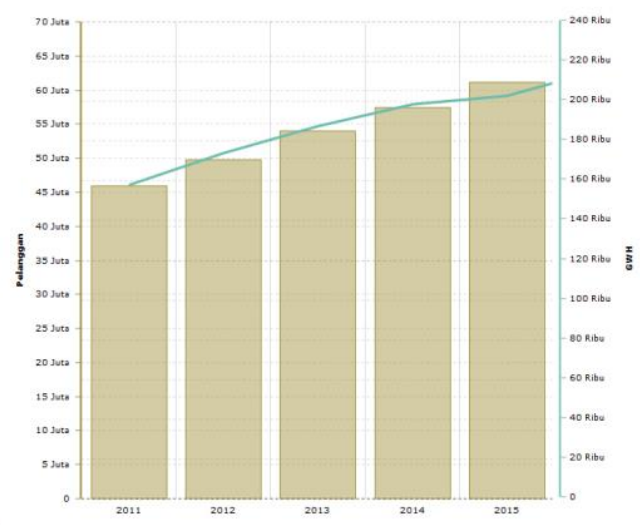

Gbr. 1 Grafik Jumlah Pelanggan Listrik Negara

(Sumber : BPS Indonesia)

Berdasarkan gambar 1 dapat dijelaskan bahwa jumlah pelanggan dari tahun ke tahun semakin meningkat. Hal ini didasarkan atas kebutuhan pelanggan khususnya masyarakat semakin meningkat di era teknologi sekarang. Berdasarkan permasalahan diatas, peneliti ingin melakukan pengolahan data secara maksimal berdasarkan sumber data yang diperoleh dari Badan Pusat Statistik (BPS) Indonesia. Banuak cabang ilmu komputer yang dapat dimanfaatkan untuk mengekstrak data dalam skala besar. Salah satunya adalah dataminig[1]-[3], jaringa saraf tiruan[4], [5][6], [7][8], sistem pendukung keputusan[9]-[13], sistem pakar [14]-[17]dan lain lain. Dari cabang ilmu kecerdasan buatan, prediksi adalah salah satu hal yang menarik untuk diteliti.

Jaringan Saraf Tiruan (JST) merupakan suatu model kecerdasan yang diilhami dari struktur otak manusia dan kemudian diimplementasikan menggunakan program komputer yang mampu menyelesaikan sejumlah proses perhitungan selama proses pembelajaran berlangsung. Salah satu algoritma JST adalah perceptron, multi perseptron, kohonen, backpropogation. Peneliti menggunakan algortima backpropogation untuk membuat model arsitektur prediksi pada jumlah pelanggan listrik PLN mengingat backpropagation adalah algoritma pembelajaran untuk memperkecil tingkat error dengan cara menyesuaikan bobotnya berdasarkan perbedaan output dan target yang diinginkan. Backpropagation juga merupakan sebuah metode sistematik untuk pelatihan multilayer JST[8], [12]. Banyak judul artikel ilmiah terkait tentang prediksi dengan model backpropogation. Salah satunya adalah [12] dengan judul “JST Dalam Memprediksi Sukuk Negara Ritel Berdasarkan Kelompok Profesi Dengan Backpropogation Dalam Mendorong Laju Pertumbuhan Ekonomi". Resume dari penelitian ini adalah membuat model prediksi SNR dengan 
masukan PNS (X1), Pegawai Swasta (X2), IRT (X3), Wiraswasta (X4), TNI/Polri (X5) dan Lainnya (X6) dengan model arsitektur pelatihan dan pengujian sebanyak 6 arsitektur yakni 6-2-1, 6-5-1, 6-2-5-1 dan 6-5-2-1. Keluaran (output) yang dihasilkan adalah pola terbaik dari arsitektur JST. Model arsitektur terbaik adalah 6-5-2-1 dengan epoch 37535, MSE 0,0009997295 dan tingkat akurasi 100\%. Dari model ini dilakukan analisis sensivitas untuk melihat variabel yang memiliki performa terbaik dan diperoleh variabel Pegawai Swasta (X2) dengan skor 0,3268. Sehingga didapat hasil prediksi investor terbanyak pada pembelian sukuk untuk seri 008 berikutnya berdasarkan kategori profesi adalah Pegawai Swasta. Diharapkan hasil penelitian ini dapat memberikan masukan kepada pihak PLN dalam memprediksi jumlah pelanggan yang menggunakan jasa PLN tersebut

\section{A. Kecerdasan Buatan}

\section{TINJAUAN PUSTAKA}

Satu bagian dari ilmu komputer yang mempelajari bagaimana membuat mesin (komputer) dapat melakukan pekerjaan seperti dan sebaik yang dilakukan oleh manusia bahkan bisa lebih baik daripada yang dilakkaun manusia[12][4]-[7].

\section{B. Jaringan Saraf Tiruan (JST)}

JST merupakan salah satu representasi buatan otak manusia yang selalu mencoba untuk mensimulasikan proses pembelajaran pada otak manusia[18][19]-[21].

\section{Algoritma Backpropogation}

Backpropagation melatih jaringan untuk mendapatkan keseimbangan antara kemampuan jaringan untuk mengenali pola yang digunakan selama pelatihan serta kemampuan untuk memberikan respon yang benar terhadap pola masukan yang serupa dengan pola yang dipakai selama pelatihan[22].

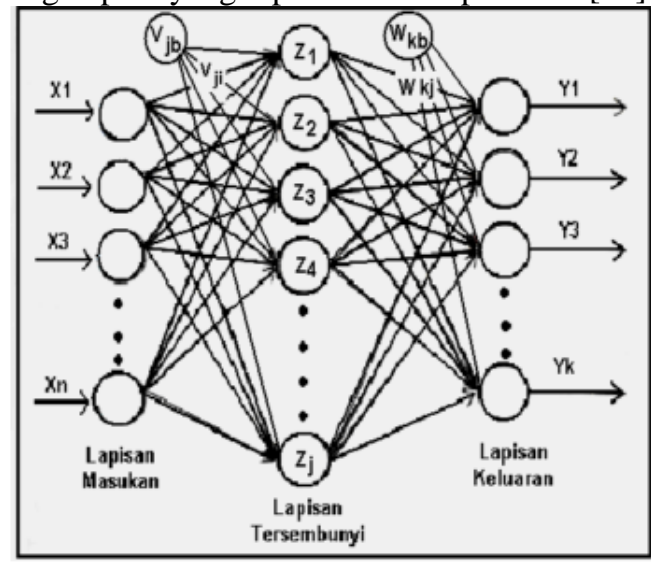

Gbr. 3 Algoritma Backpropogation

\section{METODE PENELITIAN}

Adapun langkah - langkah/ tahapan yang dilakukan untuk menyelesaikan masalah penelitian disusun dalam kerangka kerja berikut

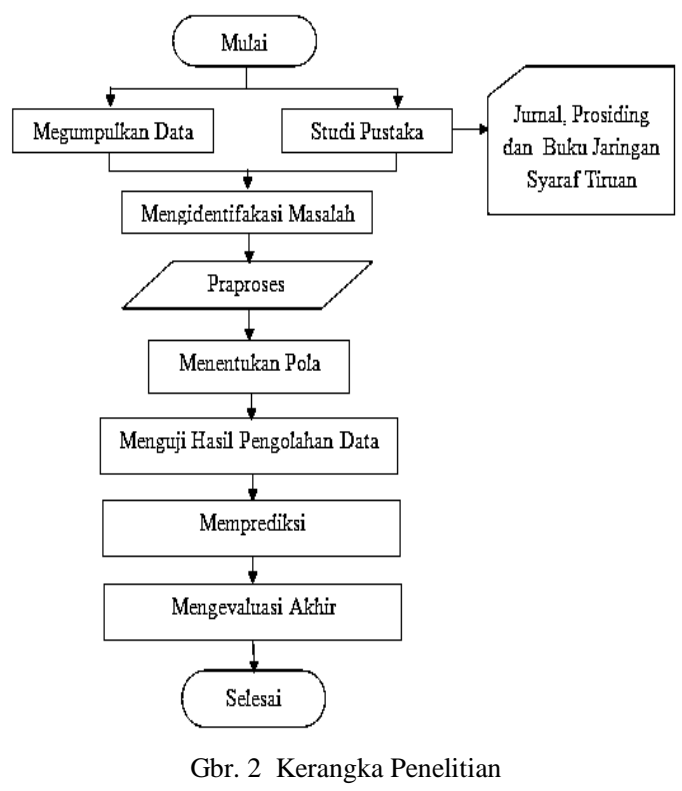

Berdasarkan kerangka kerja pada gambar diatas maka masingmasing langkah dapat diuraikan sebagai berikut :

1. Mengumpulkan Data

data-data diperoleh dari Badan Pusat Statistik indonesia melalui https://www.bps.go.id

2. Studi Pustaka

Dilakukan untuk melengkapi pengetahuan dasar dan teori-teoriyang digunakan dalam penelitian (artikel ilmiah, buku, prosiding dll)

3. Mengidentifikasi Masalah

Dilakukan setelah semua data-data terpenuhi kemudian didapatkan dataset yang sesuai untuk dilakukan proses pada tahap konversi data yang didapat sesuai dengan bobot yang ditentukan

4. Praproses

Tahapan yang dikerjakan dengan melakukan perubahan terhadap beberapa tipe data pada atribut dataset dengan tujuan untuk mempermudah pemahaman terhadap isi record, juga melakukan seleksi dengan memperhatikan konsistensi data, missing value dan redundant pada data.

5. Menentukan Model

Hasil dari tahap ini adalah model arsitektur JST dengan Backpropagation dalam menentukan pola

6. Menguji Hasil Pengolahan Data

Seteleh proses penentuan model selesai, maka dilakukan tahapan uji coba terhadap hasil pengolahan data dengan menggunakan Software Matlab

7. Memprediksi

Prediksi dilakukan untuk membandingkan hasil dengan metode Backpropagation yang paling akurat

8. Mengevaluasi Akhir

Dilakukan untuk mengetahui apakah testing hasil pengolahan data sesuai dengan yang diharapkan. 


\section{HASIL DAN PEMBAHASAN}

A. Penetapan Masukan dan Keluaran

Data jumlah pelanggan PLN yang diolah dengan metode Backpropagation dinormalisasi ke bentuk bilangan numerik 0-1 agar dapat dikenali oleh JST. Luaran yang dihasilkan mempunyai nilai range 0-1 karena menggunakan fungsi aktivasi sigmoid biner (logsig). Data akan dibagi menjadi 2 bagian, yakni data pelatihan dan data pengujian. Setiap data memiliki input dan output yang berbeda untuk mencari model arsitektur Backpropagation terbaik yang digunakan untuk memprediksi jumlah pelanggan PLN. Adapun variabel masukan JST tentang jumlah pelanggan dikelompokkan berdasarkan kelompok pelanggan yaitu: Sosial (X1), Rumah Tangga (X2), Bisnis (X3), Industri (X4) dan Publik (X5). Adapun variabel luaran adalah jumlah pelanggan PLN tahun (2006-2015). Hasil yang diinginkan pada tahap ini adalah terdeteksinya suatu nilai untuk penentuan pola arsitektur terbaik dari serangkaian penentuan pola yang dilakukan. Kategorisasi pola terbaik untuk memprediksi jumlah pelanggan PLN dengan menentukan tingkat error minimum. Semakin kecil error minimun yang dihasilkan suatu target, maka penentuan pola arsitektur terbaik semakin bagus. Untuk penelitian ini nilai error minimun yang terbaik berkisar diantara 0,009 - 0,001.

\section{B. Pengolahan Data}

Pengolahan data yang dilakukan dengan menormalisasi data jumlah pelanggan PLN (2006-2015) ke range 0-1 dengan rumus :

$$
\mathrm{xi}=\frac{0.8(\mathrm{x}-\mathrm{a})}{\mathrm{b}-\mathrm{a}}+0.1
$$

Dimana

$$
\begin{array}{ll}
\mathrm{x}^{1} & =\text { Hasil konversi data } \\
\mathrm{x} & =\text { Nilai yang akan dikonversi } \\
\mathrm{a} & =\text { Nilai minimum dari suatu data } \\
\mathrm{b} & =\text { Nilai maksimum dari suatu data }
\end{array}
$$

Sebelum data ditranformasi, data input dibagi menjadi 2 bagian, yakni data pelatihan (2006-2011) dan data pengujian $(2012$ - 2015) sehingga diperoleh data sebagai berikut : TABEL I

DATA TRAINING

\begin{tabular}{|l|r|r|r|r|r|}
\hline $\begin{array}{l}\text { Kelompok } \\
\text { Pelanggan }\end{array}$ & $\mathbf{2 0 0 6}$ & $\mathbf{2 0 0 7}$ & \multicolumn{1}{c|}{$\mathbf{2 0 0 8}$} & \multicolumn{1}{c|}{$\mathbf{2 0 0 9}$} & \multicolumn{1}{c|}{ Target } \\
\hline Sosial (X1) & 748558 & 790781 & 838129 & 861067 & 909312 \\
\hline R. Tangga (X2) & 33118262 & 34684540 & 36025071 & 37099830 & 39326344 \\
\hline Bisnis (X3) & 1511069 & 1610574 & 1716046 & 1879429 & 1912155 \\
\hline Industri (X4) & 46366 & 46818 & 47536 & 47900 & 50319 \\
\hline Publik (X5) & 182713 & 201016 & 217304 & 229459 & 240730 \\
\hline
\end{tabular}

Berdasarkan tabel 1, data training akan dinormalisasikan dengan menggunakan rumus (1). Hasil normalisasi data dapat dilihat pada tabel berikut:

$$
\text { TABEL } 2
$$

DATA TRAINING NORMALISASI

\begin{tabular}{|l|c|c|c|c|c|}
\hline Kelompok Pelanggan - PLN & $\mathbf{2 0 0 6}$ & $\mathbf{2 0 0 7}$ & $\mathbf{2 0 0 8}$ & $\mathbf{2 0 0 9}$ & Target \\
\hline Sosial (X1) & 0,11430 & 0,11516 & 0,11613 & 0,11659 & 0,11758 \\
\hline Rumah Tangga (X2) & 0,77356 & 0,80546 & 0,83276 & 0,85465 & 0,90000 \\
\hline Bisnis (X3) & 0,12983 & 0,13186 & 0,13401 & 0,13733 & 0,13800 \\
\hline Industri (X4) & 0,10000 & 0,10001 & 0,10002 & 0,10003 & 0,10008 \\
\hline
\end{tabular}
\begin{tabular}{|l|l|l|l|l|}
0,10278 & 0,10315 & 0,10348 & 0,10373 & 0,10396 \\
\hline
\end{tabular}

TABEL 3

DATA TESTING

\begin{tabular}{|l|r|r|r|r|r|}
\hline $\begin{array}{l}\text { Kelompok } \\
\text { Pelanggan }\end{array}$ & \multicolumn{1}{|c|}{$\mathbf{2 0 1 1}$} & $\mathbf{2 0 1 2}$ & \multicolumn{1}{c|}{$\mathbf{2 0 1 3}$} & \multicolumn{1}{c|}{$\mathbf{2 0 1 4}$} & \multicolumn{1}{c|}{ Target } \\
\hline Sosial (X1) & 963769 & 1033124 & 1114073 & 1182086 & 1261839 \\
\hline R. Tangga (X2) & 42592962 & 46254481 & 50145466 & 53352906 & 56649029 \\
\hline Bisnis (X3) & 2049618 & 2218425 & 2418594 & 2613834 & 2895276 \\
\hline Industri (X4) & 52215 & 52789 & 57408 & 60143 & 65353 \\
\hline Publik (X5) & 254190 & 271647 & 295699 & 330200 & 343065 \\
\hline
\end{tabular}

Berdasarkan tabel 3, data testing akan dinormalisasikan dengan menggunakan rumus (1). Hasil normalisasi data dapat dilihat pada tabel berikut:

TABEL 4

DATA TESTING NORMALISISAI

\begin{tabular}{|l|c|c|c|c|c|}
\hline Kelompok Pelanggan - PLN & $\mathbf{2 0 1 1}$ & $\mathbf{2 0 1 2}$ & $\mathbf{2 0 1 3}$ & $\mathbf{2 0 1 4}$ & Target \\
\hline Sosial (X1) & 0,11288 & 0,11387 & 0,11501 & 0,11597 & 0,11710 \\
\hline Rumah Tangga (X2) & 0,70132 & 0,75307 & 0,80807 & 0,85341 & 0,90000 \\
\hline Bisnis (X3) & 0,12823 & 0,13062 & 0,13345 & 0,13621 & 0,14019 \\
\hline Industri (X4) & 0,10000 & 0,10001 & 0,10007 & 0,10011 & 0,10019 \\
\hline Publik (X5) & 0,10285 & 0,10310 & 0,10344 & 0,10393 & 0,10411 \\
\hline
\end{tabular}

Berdasarkan tabel 2 dan 4, normalisasi data jumlah pelanggan terdiri dari 10 data dimana data ini dibagi menjadi 2 bagian. Data pelatihan (traning) terdiri dari data tahun 2016-2010 dengan target 2010. Data pengujian (testing) terdiri dari data tahun 2011-2015 dengan target 2015. Model arsitektur yang digunakan adalah 5-10-1; 5-25-1; 5-10-25-1 dan 5-25-10-1 dengan menggunakan tools Matlab dengan parameter:

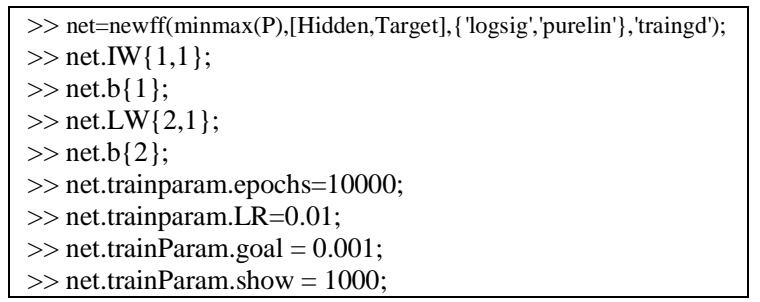

Dari pelatihan dan pengujian model arsitektur tersebut diperoleh hasil bahwa model arsitektur 5-25-1 pengujian seperti berikut:

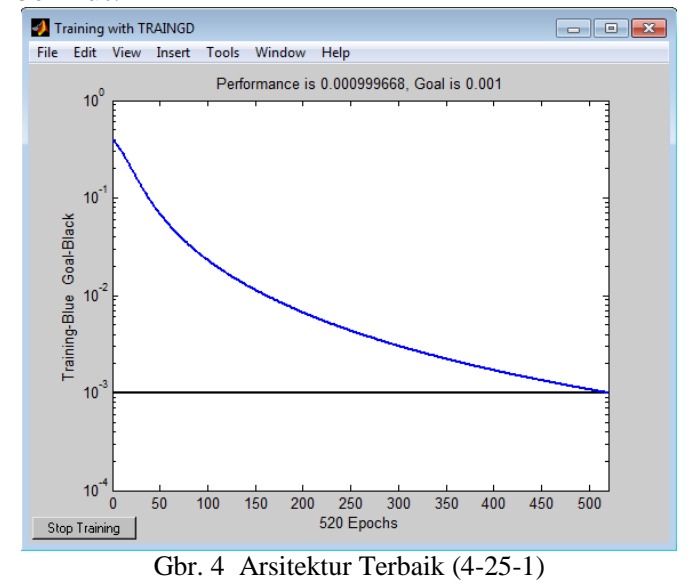


Berdasarkan gambar 4, dapat dijelaskan bahwa proses pelatihan jaringan berhenti di epoch 520 dengan target goal 0,001 . Berikut ini hasil lengkap hasil pelatihan dan pengujian data dengan model arsitektur 4-25-1

TABEL 5

HASIL DATA TRAINING

\begin{tabular}{|c|c|c|c|c|c|}
\hline \multirow[b]{2}{*}{ No } & \multirow[b]{2}{*}{ Real } & \multirow[b]{2}{*}{ Target } & \multicolumn{3}{|c|}{$5-25-1$} \\
\hline & & & Output & Error & SSE \\
\hline 1 & Sosial (X1) & 0,1176 & 0,1174 & 0,000 & 0,0000000324 \\
\hline 2 & Rumah Tangga (X2) & 0,9000 & 0,8296 & 0,070 & 0,0049561600 \\
\hline 3 & Bisnis (X3) & 0,1380 & 0,1374 & 0,001 & 0,0000003600 \\
\hline 4 & Industri (X4) & 0,1001 & 0,1053 & $-0,005$ & 0,0000272484 \\
\hline 5 & Publik (X5) & 0,1040 & 0,1076 & $-0,004$ & 0,0000132496 \\
\hline & & & & Total & 0,0049970504 \\
\hline & & & & MSE & 0,0009994101 \\
\hline
\end{tabular}

TABEL 6

HASIL DATA TESTING

\begin{tabular}{|c|c|c|c|c|c|c|}
\hline \multirow{2}{*}{ No } & \multirow{2}{*}{ Real } & \multirow{2}{*}{ Target } & \multicolumn{4}{|c|}{ ANN 5-25-1 } \\
\hline & & & Output & Error & SSE & Hasil \\
\hline 1 & Sosial (X1) & 0,1171 & 0,1166 & 0,001 & 0,0000002500 & Benar \\
\hline 2 & Rumah Tangga (X2) & 0,9000 & 0,8242 & 0,076 & 0,0057456400 & Salah \\
\hline 3 & Bisnis (X3) & 0,1402 & 0,1362 & 0,004 & 0,0000159201 & Benar \\
\hline 4 & Industri (X4) & 0,1002 & 0,1054 & $-0,005$ & 0,0000271441 & Benar \\
\hline 5 & Publik (X5) & 0,1041 & 0,1077 & $-0,004$ & 0,0000128881 & Benar \\
\hline & & & & Total & 0,0058018423 & 80 \\
\hline
\end{tabular}

Berdasarkan hasil yang ditunjukkan pada tabel 5 dan 6 dapat dijelaskan bahwa hasil data testing menunjukkan akurasi kebenaran mencapai $80 \%$ dengan error minimum berkisar diantara 0,001-0,009 dengan Means Square Error (MSE) Pelatihan 0,0009994101 dan Means Square Error (MSE) Pengujian 0,0011603685.

\section{Penetapan Model Arsitektur Terbaik}

Dari hasil serangkaian uji coba yang dilakukan dengan menggunakan 4 model arsitektur Jaringan Saraf Tiruan dengan metode backpropogation diperoleh saru model arsitektur terbaik dengan mempertimbangkan beberapa parameter MSE, epoch, akurasi kebenaran dan waktu seperti yang ditunjukkan pada tabel berikut:

TABEL 7

HASIL SERANGKAIAN UJI COBA

\begin{tabular}{|l|c|c|c|c|}
\hline Parameter & $\mathbf{5 - 1 0 - 1}$ & $\mathbf{5 - 2 5 - 1}$ & $\mathbf{5 - 1 0 - 2 5 - 1}$ & $\mathbf{5 - 2 5 - 1 0 - 1}$ \\
\hline $\begin{array}{l}\text { MSE } \\
\text { Pelatihan }\end{array}$ & 0,0009999869 & 0,0009994101 & 0,0009982633 & 0,0009990001 \\
\hline $\begin{array}{l}\text { MSE } \\
\text { Pengujian }\end{array}$ & 0,0009868421 & 0,0011603685 & 0,0036819269 & 0,0010738737 \\
\hline Epoch & 1931 & 520 & 1525 & 534 \\
\hline Akurasi & $20 \%$ & $80 \%$ & $20 \%$ & $20 \%$ \\
\hline
\end{tabular}

Berdasarkan hasil yang ditunjukkan pada tabel 7 lewat serangkaian pelatihan dan pengujian didapat model arsitektur terbaik untuk prediksi jumlah pelanggan pada periode selanjutnya adalah model arsitektur 5-25-1 dengan pertimbangan epoch dan akurasi kebenaran dalam mengenali objek yang diberikan

\section{KESIMPULAN}

Dari hasil penelitian dapat disimpulkan:

1. Jaringan saraf tiruan dengan menggunakan motode backpropagation dapat digunakan untuk memprediksi jumlah pengguna listrik PLN dengan tingkat akurasi kebenaran $80 \%$

2. Dari 4 model arsitektur yang digunakan, tidak menjamin penambahan hidden dapat meningkatkan akurasi kebenaran dalam mengenali sebuah objek. Untuk model arsitektur 5-10-25-1 dan 5-25-10-1 adalah model dengan epoch tercepat setelah arsitektur 5-25-1

\section{DAFTAR PUSTAKA}

[1] A. P. Windarto, "Penerapan Data Mining Pada Ekspor BuahBuahan Menurut Negara Tujuan Menggunakan K-Means Clustering," Techno.COM, vol. 16, no. 4, pp. 348-357, 2017.

A. P. Windarto, "Implementation of Data Mining on Rice Imports by Major Country of Origin Using Algorithm Using K-Means Clustering Method," Int. J. Artif. Intell. Res., vol. 1, no. 2, pp. 2633, 2017.

M. G. Sadewo, A. P. Windarto, and D. Hartama, "PENERAPAN DATAMINING PADA POPULASI DAGING AYAM RAS PEDAGING DI INDONESIA BERDASARKAN PROVINSI MENGGUNAKAN K-MEANS CLUSTERING," InfoTekJar (Jurnal Nas. Inform. dan Teknol. Jaringan), vol. 2, no. 1, pp. 60-67, 2017.

Sumijan, A. P. Windarto, A. Muhammad, and Budiharjo, "Implementation of Neural Networks in Predicting the Understanding Level of Students Subject," Int. J. Softw. Eng. Its Appl., vol. 10, no. 10, pp. 189-204, 2016.

[5] A. P. Windarto, L. S. Dewi, and D. Hartama, "Implementation of Artificial Intelligence in Predicting the Value of Indonesian Oil and Gas Exports With BP Algorithm," Int. J. Recent Trends Eng. Res. vol. 3, no. 10, pp. 1-12, 2017.

[6] A. Wanto, A. P. Windarto, D. Hartama, and I. Parlina, "Use of Binary Sigmoid Function And Linear Identity In Artificial Neural Networks For Forecasting Population Density," Int. J. Inf. Syst. Technol., vol. 1, no. 1, pp. 43-54, 2017

[7] A. Wanto and A. P. Windarto, "Analisis Prediksi Indeks Harga Konsumen Berdasarkan Kelompok Kesehatan Dengan Menggunakan Metode Backpropagation,” J. Penelit. Tek. Inform., vol. 2, no. 2, pp. 37-44, 2017.

[8] M. N. H. Siregar, "Neural Network Analysis With Backpropogation In Predicting Human Development Index ( HDI ) Component by Regency / City In North Sumatera," I n te r n a t i o n a l Jo u r n a lOfIn formation Syst e m Te c h n o logy, vol. 1, no. 1, pp. 22-33, 2017.

[9] Agus Perdana Windarto, "Implementasi metode topsis dan saw dalam memberikan reward pelanggan," Kuтрul. J. Ilти Koтрut., vol. 4, no. 1, pp. 88-101, 2017.

[10] T. Imandasari and A. P. Windarto, "Sistem Pendukung Keputusan dalam Merekomendasikan Unit Terbaik di PDAM Tirta Lihou Menggunakan Metode Promethee," J. Teknol. dan Sist. Komput., vol. 5, no. 4, p. 159, 2017.

[11] D. R. Sari, A. P. Windarto, D. Hartama, and S. Solikhun, "Sistem Pendukung Keputusan untuk Rekomendasi Kelulusan Sidang Skripsi Menggunakan Metode AHP-TOPSIS," J. Teknol. dan Sist. Komput., vol. 6, no. 1, p. 1, 2018.

[12] Solikhun, A. P. Windarto, Handrizal, and M.Fauzan, "Jaringan Saraf Tiruan Dalam Memprediksi Sukuk Negara Ritel Berdasarkan Kelompok Profesi Dengan Backpropogation Dalam Mendorong Laju Pertumbuhan Ekonomi," Kuтpul. J. Ilmи Komput., vol. 4, no. 2, pp. 184-197, 2017.

[13] M. Mesran, G. Ginting, S. Suginam, and R. Rahim, "Implementation of Elimination and Choice Expressing Reality ( ELECTRE ) Method in Selecting the Best Lecturer ( Case Study STMIK BUDI DARMA )," Int. J. Eng. Res. Technol., vol. 6, no. 2, NaN-2017, pp. 141-144, 2017.

[14] I. Chen and B. L. Poole, "Performance Evaluation of Rule Grouping on a Real-Time Expert System Architecture," vol. 6, no. 6, pp. 883891, 2014.

[15] Y. Malhotra, "Expert systems for knowledge management: crossing the chasm between information processing and sense making," 
Expert Syst. Appl., vol. 20, no. 1, pp. 7-16, 2001.

[16] M. Min, "A rule based expert system for analysis of mobile sales data on fashion market," 2013 Int. Conf. Inf. Sci. Appl. ICISA 2013, 2013.

[17] M. Mohammadi and S. Jafari, "An expert system for recommending suitable ornamental fish addition to an aquarium based on aquarium condition," arXiv Prepr. arXiv1405.1524, vol. 3, no. 2, pp. 1-7, 2014.

[18] Agus Perdana Windarto, "IMPLEMENTASI JST DALAM MENENTUKAN KELAYAKAN NASABAH PINJAMAN KUR PADA BANK MANDIRI MIKRO SERBELAWAN DENGAN METODE BACKPROPOGATION," J-SAKTI (Jurnal Sains Komput. dan Inform., vol. 1, no. 1, pp. 12-23, 2017.

[19] W. M. Dessy and A. Irawan, "Perbandingan Metode Jaringan Syaraf Tiruan Backpropagation Dan Learning Vector Quantization Pada Pengenalan Wajah,” J. Komput. dan Inform., vol. 1, no. 1, pp. 45-51, 2012.

[20] Z. A. Matondang, "JARINGAN SYARAF TIRUAN DENGAN ALGORITMA BACKPROPAGATION UNTUK PENENTUAN KELULUSAN SIDANG SKRIPSI," Pelita Inform. Budi Darma, vol. IV, no. 1, pp. 84-93, 2013.

[21] A. R. Youllia Indrawaty, Asep Nana Hermana, "Implementasi Model Backpropagation Dalam Mengenali Pola Gambar Untuk Mendiagnose Penyakit Kulit," J. Inform., vol. 3, no. 1, pp. 1-7, 2012.

[22] A. Jumarwanto, "APLIKASI JARINGAN SARAF TIRUAN BACKPROPAGATION UNTUK MEMPREDIKSI PENYAKIT THT DI RUMAH SAKIT MARDI RAHAYU KUDUS," J. Tek. Elektro, vol. 1, no. 1, pp. 11-21, 2009. 